\title{
A two-year study of patterns and prevalence of congenital malformations
}

\section{Sowmyanarayanan Lavanya*, Vuppu Seethalakshmi}

Department of Obstetrics and Gynecology, Narayana Medical College, Nellore, Andhra Pradesh, India

Received: 25 November 2017

Accepted: 04 December 2017

\section{*Correspondence:}

Dr. Sowmyanarayanan Lavanya,

E-mail: lav_sowgi@yahoo.com

Copyright: (C) the author(s), publisher and licensee Medip Academy. This is an open-access article distributed under the terms of the Creative Commons Attribution Non-Commercial License, which permits unrestricted non-commercial use, distribution, and reproduction in any medium, provided the original work is properly cited.

\begin{abstract}
Background: India is undergoing an epidemiological transition; communicable diseases are on the decline due to better living conditions and healthcare delivery. On the other hand, the relative increase in the prevalence of noncommunicable, chronic and genetic diseases threatens to be a public health problem in India like congenital malformations. Congenital malformations remain one of the least focused areas of disease surveillance in India compared with communicable and some chronic diseases. Thus, data on the magnitude of birth defects are essential to plan preventive strategies and organize methods of supportive care for affected individuals and families. The aim of this study is to study the incidence and prevalence of the birth defects and the patterns of congenital malformations in our institute and the various risk factors influencing the occurrence.

Methods: A cross sectional study was conducted on all Ant natal patients and deliveries conducted in the institution for a period of two years from June 2015 to May 2017. Mediscan Systems extended a big hand in further confirmation of diagnosis. A detailed history was taken regarding the patients and husband's age, parity, occupation, previous obstetric outcome, family history of birth defects and exposure to teratogens and environmental factors and intake of periconceptional folate. Data analysis was done with respect to age, parity, consanguinity, sex, previous defects.

Results: CNS defects were the most recognisable malformations at birth. Pick up rate for CVS anomalies were low requiring expertise. As against the wide prevalence of cardiac defects across total population the reported prevalence is less as similar to rest of the studies done in many centres across the country. Target scan has halved the burden of birth defects.

Conclusions: Congenital malformations though cannot be prevented totally but can be minimised and if detected early will reduce the mental agony in the mother and family. Prenatal counselling, periconceptional folate, anomaly scan, Prenatal diagnosis reduce the incidence of birth defects.
\end{abstract}

Keywords: Congenital malformations, Karyotyping, Lethal and non-lethal defects, Prenatal diagnosis, Target scan, Ultrasound

\section{INTRODUCTION}

Congenital malformations remain one of the least focused areas of disease surveillance in India compared with communicable and some chronic diseases. ${ }^{1}$ Unlike the situation in developed countries, where congenital malformations are the leading cause of infant mortality, in India low birth weight, prematurity, sepsis and infections are still the leading causes of neonatal and infant mortality. However, hospital-based studies published in the recent past have shown that birth defects are emerging as important causes of perinatal and neonatal mortality suggesting that India may be undergoing an epidemiological transition. Major 
congenital abnormalities are identified during pregnancy or shortly after birth in 2 to 3 percent of pregnancies that has cosmetic or functional significance. ${ }^{2}$ Congenital anomalies involving the brain are the largest group at 10 per 1000 live births, followed by cardiac 8 per 1000 , kidneys 4 per 1000 and limbs 1 per 1000 live births. ${ }^{3}$ Congenital malformations with cardiac defects carry the highest risk of infant deaths accounting for $28 \% .{ }^{4}$ The cause of $40-60 \%$ of the anomalies are unknown referred to as sporadic birth defects a term that implies a random occurrence and a low risk for recurrence in the subsequent pregnancy. ${ }^{5}$ The cause of 20-25\% congenital anomaly seems to be multifactorial with a complex interaction of genetic, infections, metabolic diseases, drugs and environmental factors. ${ }^{6}$ The genetic causes are numerical, structural defects and mosaicism. Downs syndrome is the commonest followed by Edward, Patau, cat eye syndromes. ${ }^{7}$ Structural anomalies are deletion, translocation and inversion. Turners and Klinefelters are sex chromosomal abnormalities. Infections like toxoplasmosis, CMV, rubella, herpes, syphilis are notable in causing defects. Uncontrolled diabetes in the organogenesis period shoots up the risk to the baby upto 5- 6\%. High HbA1c levels in the first trimester directly correlate with the incidence. Drugs like thalidomide, antiepileptics, warfarin, retinoic acid are teratogenic. ${ }^{8}$ Maternal exposure to alcohol, smoking play a risk. Deficiency of folate leads to neural tube defects in the foetus. ${ }^{9}$ Hydrocephalus, renal anomalies, abdominal wall defects, diaphragmatic hernia do not show a definitive etiology. RCOG (Royal College of Obstetricians and Gynaecologists) classified malformations into lethal, severe and moderate. Lethal defects are anencephaly, bilateral renal agenesis, giant hygroma, osteochondrio dysplasia, icthyosis congenita. Severe defects include hydrocephalus, spina bifida, esophageal atresia, TOF, absent uterus, ectodermal dysplasia, PUV, ASD, PDA. Moderate include imperforate hymen, septal deviation, choanal atresia, craniosynostosis, eyelid defects.

The rapid development of technology allowing early and accurate diagnosis of foetal disorder has revolutionised the practice of Obstetrics over 25 years. Beginning with simple cytogenetics to detect chromosomal aberration to molecular genetics help us to detect anomalies. ${ }^{10}$ Prenatal diagnosis helps in detection of major abnormalities, informative counselling, offers selective termination of pregnancy, mental preparation of the mother, intrauterine foetal therapy and optimise delivery. It is recommended for women older than 35 years, recurrent abortions, previous malformed baby, type 1 diabetes, inborn error of metabolism. Ultrasound in the first trimester around 1113 weeks can detect most of the anomalies with the added advantage of measuring the nuchal translucency. ${ }^{11}$ Target imaging for foetal anomalies done between 18-22 weeks detects all the major anomalies.

The aim and objective of the study is to analyse the incidence and prevalence of malformations in our institute for a period of two years, to assess the pattern of malformations and to assess the influence of various risk factors like age, parity, previous obstetric history, first trimester events and consanguinity.

\section{METHODS}

A hospital based cross sectional study was conducted on patients delivered at Government RSRM Hospital a tertiary care institution for a period of two years from June 2015 to May 2017. Total number of deliveries were 23850. All the booked and unbooked cases were taken into consideration.

Some cases have been diagnosed in the institute during routine ultrasound and some were referred with a report of defects for confirmation and termination. All the cases detected antenatally were analysed by a questionnaire. A detailed history was taken regarding the patients and husband's age, parity, occupation, previous obstetric outcome, family history of birth defects and exposure to teratogens and environmental factors and intake of peri conceptional folate.

Mediscan systems extended helping hand in further confirmation and prenatal diagnosis. Genetic counselling was offered to patients by the Genetic Department at Mediscan.

Prenatal diagnosis was done in indicated patients suspecting genetic etiology. Post-delivery the foetus was examined in detail for structural anomalies and admitted to NICU for further evaluation. Some of the malformed foetuses were sent for autopsy at Mediscan systems with consent. Surgically correctable anomalies were referred to Paediatric Surgery Department. Mother was given genetic counselling before discharge from the hospital and she was instructed regarding future conceptions and the importance of intake of periconceptional folate. Defects which caused serious structural, cosmetic and functional disability requiring surgical or medical management were classified as major anomalies. The major defects were classified into central nervous system, cardiac, skeletal, gastro-intestinal, genito urinary and miscellaneous disorders.

The babies were followed up in well baby clinics. Detailed history and thorough physical examination was done. Various imaging modalities like radiography, ultrasound, CT Scan and MRI were done as per requirement. The anomalies diagnosed on pre-natal ultrasonography were confirmed clinically or by appropriate radio-diagnostic methods soon after birth. The neonates were managed accordingly either medically or surgically.

Postoperative outcome in terms of morbidity and mortality was noted. Analysis of the data was done using simple statistical method of recording number and percentage of cases. Data analysis was done with respect to age, parity, consanguinity, sex, previous defects. 


\section{RESULTS}

The bulk of our deliveries are confined to age group 2125 years. There is no actual correlation between age and defects (Table 1).

Table 1: Distribution of cases with age.

\begin{tabular}{|lll|}
\hline Age & No. of cases & Percentage \\
\hline$<20$ & 71 & $21 \%$ \\
\hline $21-25$ & 161 & $49 \%$ \\
\hline $26-30$ & 81 & $24 \%$ \\
\hline $31-35$ & 14 & $4 \%$ \\
\hline$>36$ & 7 & $2 \%$ \\
\hline Total & 334 & $100 \%$ \\
\hline
\end{tabular}

In the study parity does not influence the occurrence of defects. No correlation could be made out between consanguineous marriage and defects. $24 \%$ of the patients with consanguinity had malformed foetus. With regard to sex of the baby the malformations showed a predilection to male sex (Table 2).

Table 2: Distribution of cases with sex.

\begin{tabular}{|lll|}
\hline Sex & No. of cases & Percentage \\
\hline Male & 176 & $53 \%$ \\
\hline Female & 146 & $44 \%$ \\
\hline Ambiguous & 12 & $3 \%$ \\
\hline Total & 334 & $100 \%$ \\
\hline
\end{tabular}

Around $22 \%$ of the malformed babies were born to mothers with previous history of pregnancy wastage and $11 \%$ had previously malformed babies showing genetic cause in the etiology. The outcome of malformations is dependent on the gestational age of detection. Earlier they are picked up, more the number of recommended MTP's. $7.3 \%$ of the MTP were done for malformations. Maternal febrile illness in the first trimester had a definite predilection for malformations. Infants of diabetic mothers showed higher cardiac and neural defects. One baby had fetal hydantoin syndrome whose mother had taken phenytoin during pregnancy. TORCH screening is not routinely done for all patients but three patients with recurrent pregnancy loss showed increased titre.

The prevalence of congenital malformations is 140 per 10000 live births.

Central nervous system defects were the most recognisable malformations at birth and formed the bulk of defects accounting for 74 per 10000. CNS malformations were better detected in the antenatal ultrasound than any other systems and most of the anomalies are potentially lethal hence accounting for the higher numbers. CNS defects are obvious to the room personnel requiring no additional confirmation by investigations and imaging. Anencephaly was the most reported CNS defect followed by spinal defects.
Periconceptional folate was not taken by the patients only post conceptional intake is reported (Table 3 ).

Table 3: Incidence of various malformations.

\begin{tabular}{|ll|}
\hline System & Incidence \\
\hline CNS & 178 \\
\hline Syndromes & 62 \\
\hline CVS & 26 \\
\hline Skeletal & 23 \\
\hline Face & 20 \\
\hline Gut & 11 \\
\hline Diaphragmatic hernia & 6 \\
\hline Git & 7 \\
\hline Sacrococcygeal teratoma & 1 \\
\hline
\end{tabular}

Table 4: Malformations detected by ultrasound.

\begin{tabular}{|lll|}
\hline & No. of cases & Percentage \\
\hline Detected & 249 & $75 \%$ \\
\hline Not detected & 49 & $15 \%$ \\
\hline USG not done & 36 & $10 \%$ \\
\hline
\end{tabular}

As against the wide prevalence of cardiac defects across total population the reported prevalence is less as similar to rest of the studies done in many centres across the country.

Table 5: Outcome in malformed foetuses.

\begin{tabular}{|ll|}
\hline Outcome & Cases \\
\hline Live births & 131 \\
\hline MTP & 152 \\
\hline IUD & 61 \\
\hline
\end{tabular}

The pickup rate and detection of cardiovascular defects were very low requiring expertise and high-resolution imaging.

Table 6: Gestational age at which malformations were detected.

\begin{tabular}{|l|l|}
\hline Gestational age & Number \\
\hline $1^{\text {st }}$ trimester & 47 \\
\hline $2^{\text {nd }}$ trimester & 198 \\
\hline $3^{\text {rd }}$ trimester & 89 \\
\hline
\end{tabular}

The various gastro intestinal anomalies were duodenal atresia, TE fistula, omphalocele, gastroschisis, imperforate anus. The various Genitourinary anomalies are posterior urethral valve, renal agenesis, polycystic kidney and multicystic dysplastic kidney. The various skeletal anomalies are polydactyly, syndactyly, short limbs, CTEV, skeletal dysplasia, achondroplasia. Target or anomaly scan has halved the burden of birth defects and helps the mother to prepare herself for termination and plan the future pregnancies. $75 \%$ of the anomalies were picked by ultrasound in the present study. $15 \%$ of the cases were however missed by the routine ultrasound 
done at primary levels without a Sonologist. $10 \%$ of the mothers had no ultrasound scan done in their pregnancy. Around $3 \%$ of the anomalies were picked up in the third trimester which were unnoticed in the previous scans (Table 4).

\section{DISCUSSION}

The Global incidence of congenital malformations detected at birth is 2-3\% with a higher incidence in India. However, there is no systematic surveillance existing for birth defects in India. In studies from other parts of India, the incidence varied from $0.3 \%$ to $3.6 \%$. The rate in the present study is comparable to the studies from Varanasi, Manipal and Allahabad. A higher incidence of congenital malformations has been reported from centres like PGIMER Chandigarh and JIPMER Pondicherry, which may be because of higher autopsy rates at these centres.

Birth defects registry of India statistics:

- The overall crude birth defect prevalence is 92.2 per 10000 .

- The prevalence was highest in Mumbai followed by Hyderabad, Chennai and least from West Godavari.

- CNS defects and neural tube defects were the most prevalent among system defects across regions.

- The prevalence of major anomalies was 26/10000 NTD followed by $7.5 / 10000$ talipes and least $1.7 / 10000$ renal cystic anomalies. ${ }^{12}$

The reasons behind less prevalence of cardiac defects are:

- The pickup rate and detection of cardiovascular defects were very low requiring expertise and highresolution imaging

- Most of the minor cardiac anomalies were not detected at birth and show up symptoms later in the early or late neonatal periods unlike major complex cardiac anomalies which manifest in the labour room itself

- Cardiac defects need to be reconfirmed after birth by ECHO and Doppler which are reported later.

- Post-natal follow up too pick up cases of cardiac defects.

From this it is inferred that still cardiac defects form the core of birth defects for which we need to expertise upon their detection rate and prevention.

Congenital malformations account for $20 \%$ of the perinatal mortality. Occurrence of birth defects cannot be prevented but detection is possible with the advent of high resolution and high technology ultrasound and expertise. Detection in the early antenatal period will reduce the mental agony of the mother and family and lead them to decide the choice of termination or continuation. Proper planning of time of pregnancy, pre pregnant counselling, periconceptional folate intake, scan at 11-13 weeks with triple testing and target scan with methodical imaging and prenatal diagnosis in high risk mothers will definitely address a solution to birth defects. ${ }^{13}$ It has become our professional responsibility to identify those couples at risk of having a malformed and abnormal foetus. ${ }^{14}$ Early antenatal diagnosis will lead to early termination of pregnancy with lethal defects which will in turn decrease the maternal morbidity and mental health of the mother. In utero treatment can be planned well if the defects are surgically correctable. Early neonatal interventions can also be timed to avoid unnecessary delay in the treatment. ${ }^{15}$

\section{CONCLUSION}

To conclude congenital malformations cannot be prevented totally, can be minimised and when detected earlier in ultrasound can be tackled by termination in case of lethal anomalies and intervened in moderate anomalies thereby reducing the burden of an abnormal and dependable child in the society. It has become our professional responsibility to identify the couples at risk of having abnormal foetus. Given the available health standards majority of the defects can be detected if proper counselling is given to the patient and proper screening is done by the qualified sonologist. Broader the diagnosis of birth defects made if Obstetricians, Perinatologist, Sonologist and laboratory personnel work hand in hand.

Funding: No funding sources Conflict of interest: None declared

Ethical approval: The study was approved by the Institutional Ethics Committee

\section{REFERENCES}

1. Patel ZM, Adhia RA. Birth defects surveillance study. Indian J Pediatr. 2005;72:489-91.

2. Agarwal SS, Singh U, Singh PS, Singh SS, Das V, Sharma A, et al. Prevalence and spectrum of congenital malformations in a prospective study at a teaching hospital. Indian J Med Res. 1991;94:413.

3. Kalra A, Kalra K, Sharma V, Singh M, Dayal RS. Congenital malformations. Indian Pediatr. 1984;24:945-50.

4. Mohanty C, Mishra OP, Das BK, Bhatia BD, Singh G. Congenital cardiac malformation in newborn: A study of 10,874 consecutive births. J Anat Soc India. 1989;38:101-11.

5. Sugunabi NS, Mascarane M, Syamala K, Nair PM. An etiological study of congenital malformations in new born. Indian Pediatr. 1982;19:1003-7.

6. Chaturvedi P, Benerjee KS. Spectrum of congential malformations in the newborn from rural Maharashtra. Indian J Pediatr. 1989;6:501-7. 
7. Matsunga E, Oishi TA. Reexamination of paternal age effect in Down's syndrome. Human Genetics. 1978;40(3):259-68.

8. Brent RL. Utilization of animal studies to determine the effect and risk of Environmental toxicants, drugs (chemicals, and physical agents). Paed. 2004;113:984.

9. De Wals P, Trochet C, Pinsonneault L. Prevalence of neural tube defect in the province of Quebec, 1992. Can J Public Health. 1999;90:237-9.

10. Baird PA, Anderson TW, Newcombe HB. Genetic disorders. Am J Hum Genet. 1998;42:677.

11. Czeizel AE, Intody Z, Modell B. What proportion of congenital abnormalities can be prevented? $\mathrm{Br}$ Med J. 1993;306(6876):499-503.

12. Suresh S, Thangavel G, Sujatha J. Methodological issues in setting up a surveillance system for birth defects in India. Nat Med J India. 2005;18(5).
13. Nelson-Piercy C. Pre-pregnancy counselling. J Obs Gynaecol Reprod. 2003;13:273-80.

14. Ahmed AM, Elkader SA, Hamid AA, Gaafar HM. Assessment of risk factors for fetal congenital anomalies among pregnant women at Cairo university hospitals. J Am Sci. 2011;7:899-908.

15. Sridhar K. A community based survey of visible congenital anomalies in rural Tamil Nadu. Indian $\mathbf{J}$ Plast Surg. 2009;42(1);S184-91.

Cite this article as: Lavanya S, Seethalakshmi V. A two-year study of patterns and prevalence of congenital malformations. Int J Reprod Contracept Obstet Gynecol 2018;7:114-8. 